\title{
Keanekaragaman Mikroalga Chlorophyta Di Sungai Kasie Kota Lubuklinggau Provinsi Sumatera Selatan
}

\author{
Harmoko $^{1)}$, Sepriyaningsih ${ }^{2)}$ \\ ${ }^{12}$ Program Studi Pendidikan Biologi, STKIP PGRI Lubuklinggau, Sumatera Selatan \\ Email: putroharmoko@gmail.com \\ Email: sepriyaningsih26@gmail.com
}
APA Citation: Harmoko, H., Sepriyaningsih, S. (2020). Keanekaragaman Mikroalga Chlorophyta Di Sungai Kasie Kota Lubuklinggau Provinsi Sumatera Selatan. Quagga: Jurnal Pendidikan dan Biologi, 12(1), 52-56. doi: 10.25134/quagga.v12i1.2142.

\author{
Received: 15-11-2019
}

Accepted: 16-01-2020

Published: 25-01-2020

\begin{abstract}
Abstrak: Sungai memiliki banyak sekali fungsi, salah satunya yaitu sebagai ekosistem makhluk hidup. Sungai Kasie merupakan salah satu sumber air PDAM Tirta Bukit Sulap Lubuklinggau dan habitat untuk berbagai macam makhluk hidup. Chlorophyta (alga hijau) merupakan kelompok terbesar dari vegetasi alga, yang sebagian besar hidup di air tawar. Tujuan dari penelitian ini yaitu dapat menganalisis keanekaragaman mikroalga Chlorophyta di sungai Kasie Kota Lubuklinggau. Jenis penelitian yang digunakan yaitu penelitian survei. Sampel diambil dari 3 stasiun berdasarkan kriteria ekosistem yang berbeda, dengan tiga pengulangan waktu pengambilan dari bulan April-Mei 2019. hasil penelitian yang dilakukan, jenis mikroalga Chlorophyta yang ditemukan di Sungai Kasie Kota Lubuklinggau, terdiri dari: 4 Kelas, 6 Ordo, 7 Famili, 7 Genus, dan 9 Spesies. Mikroalga Chlorophyta yang ditemukan di Sungai Kasie Kota Lubuklinggau terdiri dari Microspora sp, Scenedesmus opoliensis, Scenedesmus sp, Ulothrix sp, Rhizoclonium sp, Rhizoclonium hieroglyphicum, Microthamnion sp, Stigeoclonium sp dan Bulbochaete sp. Kesimpulan dari penelitian ini adalah Nilai rata-rata keanekaragaman Chlorophyta di Sungai Kasie Kota Lubuklinggau yaitu 1,22 dalam kategori "keanekaragaman kecil/rendah".
\end{abstract}

Kata Kunci: Chlorophyta; Mikroalga; Keanekaragaman; Kota Lubuklinggau; Sungai Kasie.

\begin{abstract}
The river has many functions, one of its functions is as an ecosystem of living things. Kasie River is one of PDAM Tirta Bukit Sulap Lubuklinggau's water sources and habitat for a variety of living things. Chlorophyta (green algae) is the largest group of algal vegetation, Chlorophyta mostly live in fresh water. The purpose of this research is to be able to analyze the diversity of Chlorophyta microalgae found in the Kasie river in Lubuklinggau City. This type of research is a survey research. Samples were taken from 3 stations based on different ecosystem criteria, with three repetitions of time taken from April to May 2019. The results of the study, the type of Chlorophyta microalgae found in the Kasie River in Lubuklinggau City, consisted of: 4 Classes, 6 Orders, 7 Families , 7 Genera, and 9 Species. Chlorophyta microalgae found in the Kasie River in Lubuklinggau City consisted of Microspora sp, Scenedesmus opoliensis, Scenedesmus sp, Ulothrix sp, Rhizoclonium sp, Rhizoclonium hieroglyphicum, Microthamnion sp, Stigeoclonium sp and Bulbochaete sp. The conclusion of this study is the average value of Chlorophyta diversity in the Kasie River of Lubuklinggau City which is 1.22 in the category of "small/low diversity".

Keywords: Chlorophyta; Microalgae; Diversity; Lubuklinggau City; Kasie River.

\section{PENDAHULUAN}

Kegiatan pendataan mikroalga khususnya divisi chlorophyta sudah banyak dilakukan baik di pulau Sumatera Selatan sendiri ataupun di luar Sumatera Selatan. Sesuai dengan habitat mikroalga, mikroalga banyak ditemukan di

perairan tawar mikroalga biasanya ditemukan di Danau, Waduk, Sungai dan badan air lainnya. Khusus untuk di wilayah Sumatera Selatan khusunya di Kota Lubuklinggau, pendataan mikroalga divisi Chlorophyta sudah dilakukan dibeberapa sungai.
\end{abstract} perairan, baik asin ataupun tawar. Pada kondisi 
Chlorophyta di sungai Kati berjumlah 20 spesies (Harmoko \& Sepriyaningsih, 2017), di Sungai mesat ditemukan 17 spesies mikroalga divisi chlorophyta (Harmoko et al, 2018) dan selanjutnya di Sungai Kelingi yang ditemukan 15 spesies mikroalga divisi chlorophyta (Harmoko \& Sepriyaningsih, 2018).

Sungai merupakan aliran dan atau wadah air alami dan buatan berupa jaringan yang mengalirkan air dari hulu ke hilir (Pangestu \& Haki, 2013; Siahaan et al, 2011). Sungai yang berfungsi sebagai tempat mengalirnya air selalu ada di posisi paling terendah dalam lanskap bumi, dengan demikian kondisi sungai tidak bisa dipisahkan dari kondisi lingkungan aliran sungai tersebut. Keberadaan sungai memberikan manfaat bagi kehidupan manusia dan alam (Junaidi, 2014).

Sungai memiliki banyak sekali fungsi, salah satunya yaitu sebagai ekosistem makhluk hidup yang sangat penting (Siahaan et al, 2011). Sungai memiliki peran strategis sebagai salah satu sumber daya alam yang mendukung kehidupan masyarakat (Satriani et al, 2013).

Kota Lubuklinggau adalah salah satu kota di Sumatera Selatan yang memiliki beberapa sungai. Sungai di Kota Lubuklinggau meliputi: sungai Kelingi, sungai Mesat, sungai Malus, sungai Kati dan sungai Kasie. Sungai Kasie merupakan salah satu sumber air PDAM Tirta Bukit Sulap Lubuklinggau dan habitat untuk berbagai macam makhluk hidup. Mulai dari organisme mikroskopik hingga yang ukuran makro bias dilihat secara langsung tanpa bantuan alat. Salah satu organisme yang terdapat di perairan adalah fitoplankton (plankton menyerupai tumbuhan yang secara bebas mengapung dan hanyut dalam perairan dan dapat berfotosintesis). Fitoplankton bisa juga disebut dengan mikroalga.

Alga memiliki peran sebagai produsen dalam suatu ekosistem. Berbagai jenis alga yang hidup di air merupakan penyusun fitoplankton terutama yang tubuhnya bersel satu dan dapat bergerak aktif. Sebagian besar fitoplankton adalah anggota dari Chlorophyta (alga hijau). Chlorophyta (alga hijau) merupakan kelompok dari vegetasi alga, yang sebagian besar hidup di air tawar. Karakteristik chlorophyta mengandung pigmen klorofil a dan b lebih dominan dibandingkan karotin dan xantofil, bersifat kosmopolit, dan hidup di perairan yang intensitas cahayanya cukup seperti halnya di kolam, danau, genangan air hujan, serta air mengalir (sungai dan selokan). Dan dapat ditemukan pada lingkungan semi akuatik (Siregar, 2011).

Susunan tubuh Chlorophyta bervariasi baik dalam ukuran, bentuk maupun susunannya, bisa berupa uniselular dan motil (Chlamydomonas), uniselular dan non motil (Chlorella), sel senobium (Volvox), koloni tak beraturan (Tetraspora), dan filamen (bercabang: Oedogonium, tidak bercabang: Pithoptora).

Berdasarkan latar belakang tersebut, peneliti melakukan penelitian mikroalga Chlorophyta di sungai Kasie Kota Lubuklinggau. Tujuan dari penelitian ini yaitu dapat menganalisis keanekaragaman mikroalga Chlorophyta yang ditemukan di sungai Kasie Kota Lubuklinggau.

\section{METODOLOGI PENELITIAN}

Jenis penelitian yang digunakan adalah penelitian survei. Sampel diambil dari 3 stasiun berdasarkan kriteria ekosistem yang berbeda, dengan tiga pengulangan waktu pengambilan dari bulan April-Mei 2019. Hal-hal ini dimaksudkan untuk mengetahui variasi jenis mikroalga yang ada di Sungai (Andriansyah et al, 2014). Sampel mikroalga kemudian diamati dan diidentifikasi di Laboratorium Biologi STKIP PGRI Lubuklinggau.

Adapun alat ang digunakan dalam penelitian ini adalah plankton net ukuran 20 mesh, mikroskop listrik, $\mathrm{pH}$ meter, secchi disk, thermometer dan DO. Sedangkan bahan yang digunakan pada penelitian ini yaitu sampel air dan etanol $85 \%$.

Prosedur dalam penelitian ini yaitu: (1) menentukan stasiun pengambilan sampel mikroalga, (2) mengukur faktor fisik yaitu suhu, kecerahan, oksigen terlarut dan keasaman (pH) di masing-masing stasiun di Sungai Kasie, (3) mengambil sampel air, yang disaring dengan plankton net, (4) Sampel mikroalga selanjutnya dipindahkan dan ditampung ke botol dengan cara di semprot denga spray, (5) Sampel kemudian diberi etanol $85 \%$ 2-3 tetes, di tutup dan diberikan label, (6) melakukan hal 
yang sama pada setiap stasiun, sebanyak 3 stasiun, dan (7) sampel kemudian dianalisis dan diindentifikasi.

Analisis data yang digunakan meliputi: identifikasi jenis mikroalga secara morfologi mengacu pada berbagai macam literatur. Analisis berikutnya yang dilakukan meliputi:

a. Keanekaragaman menggunakan rumus Shanon-Wiener:

$$
\mathrm{H}=\sum_{i=1}^{s} p i \ln p i
$$

Dengan $p i \frac{n i}{N}$

Keterangan:

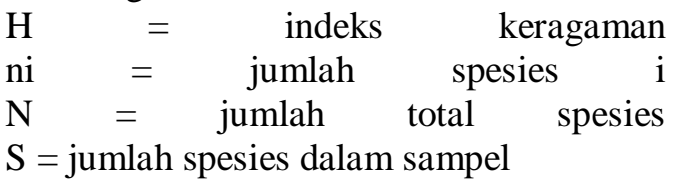

b. Dominansi:

$$
\mathrm{C}=\sum_{i=1}^{S}(\mathrm{Pi})^{2}
$$

Keterangan:

$\mathrm{C}=$ indeks dominansi

$\mathrm{Pi}=$ perbandingan proporsi spesies ke $\mathrm{i}$

$\mathrm{S}=$ Jumlah spesies yang ditemukan c. Keseragaman:

Keterangan:

$$
E=\frac{H^{\prime}}{H m a k s}
$$

$\mathrm{E}=$ Indeks Keseragaman

$\mathrm{H}^{\prime}=$ Indeks keanekaragaman jenis

$\mathrm{H}$ maks $=\ln \mathrm{s}$ dan $\mathrm{s}$ merupakan jumlah spesies yang ditemukan.

\section{HASIL DAN PEMBAHASAN}

Berdasarkan hasil penelitian yang dilakukan, jenis mikroalga Chlorophyta yang ditemukan di Sungai Kasie Kota Lubuklinggau terdapat 3 spesies yang tidak ditemukan di Sungai Kelingi, Sungi Mesat dan Sungai Kati. Spesies mikroalga tersebut adalah Microspora sp, Microthamnion sp dan Bulbochaete sp.

Secara keseluruhan, mikroalga divisi Chlorophyta yang ditemukan di Sungai Kasie terdiri dari: 4 Kelas, 6 Ordo, 7 Famili, 7 Genus, dan 9 Spesies. Spesienya terdiri dari: Microspora sp, Scenedesmus opoliensis, Scenedesmus sp, Ulothrix sp, Rhizoclonium sp, Rhizoclonium hieroglyphicum, Microthamnion sp, Stigeoclonium sp dan Bulbochaete sp.

Klasifikasi mikroalga Chlorophyta dapat dilihat pada Tabel 1 berikut ini:

Tabel 1. Mikroalga Chlorophyta di Sungai Kasie Kota Lubuklinggau

\begin{tabular}{lllll}
\hline Kelas & Ordo & Famili & Genus & Spesies \\
\hline Chlorophyceae & Sphaeropleales & Microsporaceae & Microspora & Microspora sp \\
& & Scenedesmaceae & Scenedesmus & $\begin{array}{l}\text { Scenedesmus } \text { opoliensis } \\
\text { Scenedesmus } \text { sp }\end{array}$ \\
Ulvophyceae & Ulotrichales & Ulotrichaceae & Ulothrix & $\begin{array}{l}\text { Ulothrix } \mathrm{sp} \\
\text { Cladophorales }\end{array}$ \\
& Cladophoraceae & Rhizoclonium & $\begin{array}{l}\text { Rhizoclonium } \mathrm{sp} \\
\text { Rhizoclonium } \\
\text { hieroglyphicum }\end{array}$ \\
Trebouxiophyceae & Microthamniales & Microthamniaceae & Microthamnion & Microthamnion $\mathrm{sp}$ \\
Chlorophyceae & Chaetophorales & Chaetophorales & Stigeoclonium & Stigeoclonium $\mathrm{sp}$ \\
& Oedogoniales & Oedogoniaceae & Bulbochaete & Bulbochaete $\mathrm{sp}$ \\
\hline
\end{tabular}

Mikroalga Chlorophyta yang didapat, kemudian dilakukan analisis untuk melihat keanekaragaman, dominansi dan keseragamannya. Secara detail, hasil analisis dapat dilihat pada Tabel 2 berikut ini: 
Tabel 2. Hasil Analisis Keanekaragaman, Dominansi dan Keseragaman Mikroalga Chlorophyta di Sungai Kasie Kota Lubuklinggau

\begin{tabular}{cccccc}
\hline No & Nilai & \multicolumn{3}{c}{ Stasiun } & Rata-rata \\
\cline { 3 - 5 } & & $\mathbf{1}$ & $\mathbf{2}$ & $\mathbf{3}$ & \\
\hline 1 & Keanekaragaman & 0,96 & 1,41 & 1,29 & 1,22 \\
2 & Dominansi & 0,43 & 0,271 & 0,35 & 0,35 \\
3 & Keseragaman & 0,44 & 0,64 & 0,59 & 0,56 \\
\hline
\end{tabular}

Indeks keanekaragaman (H') menyatakan keadaan suatu populasi organisme secara matematis untuk memudahkan peneliti dalam menganalisis informasi jumlah individu masing-masing bentuk pertumbuhan/genus dalam suatu komunitas habitat dasar Berdasarkan Tabel 1, nilai rata-rata keanekaragaman Chlorophyta di Sungai Kasie Kota Lubuklinggau yaitu 1,22 dengan keanekaragam tertinggi berada di stasiun 2 dengan nilai 1,41 dan terendah berada di staisun 1 dengan nilai 0,96. Berdasarkan nilai indeks keanekaragaman termasuk dalam kategori "keanekaragaman kecil" (Sari et al, 2013). Keanekaragaman jenis di suatu perairan dapat dijadikan indikator tentang tingkat pencemaran suatu perairan.

Indeks dominansi berdasarkan jumlah individu jenis digunakan untuk mengetahui tingkat dominansi kelompok biota tertentu. Persamaan yang dijadikan acuan yakni indeks dominansi, bahwa semakin tinggi nilai indeks maka akan terlihat suatu biota mendominasi substrat dasar perairan. Jika nilai indeks dominansi (C) mendekati nol, maka hal ini menunjukkan pada perairan tersebut tidak ada biota yang mendominasi dan biasanya diikuti oleh nilai keseragaman (E) yang tinggi. Sebaliknya, jika nilai indeks dominansi (C) mendekati satu, maka hal ini menggambarkan pada perairan tersebut ada salah satu biota yang mendominasi dan biasanya diikuti oleh nilai keseragaman yang rendah. Nilai rata-rata dominansi Chlorophyta di Sungai Kasie Kota Lubuklinggau yaitu 0,35 dengan dominansi tertinggi berada di stasiun 1 dengan nilai 0,43 dan terendah berada di stasiun 2 dengan nilai 0,27 . Berdasarkan nilai dominansi termasuk dalam kategori "dominansi rendah".

Sedangkan untuk nilai rata-rata keseragaman Chlorophyta di Sungai Kasie Kota Lubuklinggau yaitu 0,56 dengan keseragaman tertinggi berada di stasiun 2 dengan nilai 0,64 dan terendah berada di stasiun 1 dengan nilai 0,44. Berdasarkan nilai keseragaman termasuk dalam kategori "komunitas tertekan". Semakin kecil indeks keseragaman, semakin kecil pula keseragaman populasi, hal tersebut menunjukkan bahwa penyebaran jumlah individu setiap jenis tidak sama sehingga ada kecenderungan satu jenis biota mendominasi. Semakin besar nilai keseragaman, menggambarkan jumlah biota pada masingmasing jenis tidak jauh beda sama.

Jumlah spesies mikroalga Chlorophyta yang ditemukan di Sungai Kasie Kota Lubukllinggau termasuk sedikit jika dibandingkan dengan Sungai Kelingi yang berjumlah 15 spesies (Harmoko \& Sepriyaningsih, 2018), Sungai Mesat 17 Spesies (Harmoko et al, 2018) dan Sungai Kati yang berjumlah 20 spesies (Harmoko \& Sepriyaningsih, 2017).

Hal ini dikarenakan kondisi Sungai Kasie yang cukup deras saat dilakukan penelitian, sehingga mikroalga yang tertangkap cukup sedikit jika dibandingkan dengan sungai lain yang ada di Kota Lubuklinggau. Selain itu juga dipengaruhi oleh kondisi faktor abiotik sebagai berikut:

Tabel 3. Faktor Abiotik di Sungai Kasie Kota Lubuklinggau

\begin{tabular}{ccc}
\hline No & Faktor Abiotik & Nilai Rata-rata \\
\hline 1 & Suhu & $27^{\circ}$ \\
2 & Keasaman & 6,8 \\
3 & Kecerahan & $0,70 \mathrm{~m}$ \\
4 & Oksigen terlarut & $5,03 \mathrm{mg} / \mathrm{L}$ \\
\hline
\end{tabular}

Faktor abiotik yang diukur yaitu suhu air Sungai Kasie. Hasil suhu pada penelitian yaitu rata-rata $27{ }^{\circ} \mathrm{C}$. Suhu optimal untuk mikroalga antara $24-30{ }^{\circ} \mathrm{C}$ (Endrawati \& Riniatsih, 2013). Jadi, nilai suhu air Sungai Kasie dalam keadaan normal. Keasaman air Sungai Kasie yaitu 6,8. Menurut Maresi et al, (2015) Kisaran pH yang 
sesuai untuk kehidupan organisme perairan adalah 6,5-9. Jadi nilai keasaman air Sungai Kasie dalam keadaan normal. Hasil kecerahan pada penelitian rata-rata $0.70 \mathrm{~m}$. Menurut Maresi et al, (2015) perairan yang memiliki kecerahan intensitas cahaya 0,60 m-0,90 m dianggap cukup baik untuk keberlangsungan kehidupan ikan dan organisme perairan dan kecerahan $<0,30 \mathrm{~m}$ dapat menimbulkan masalah bagi ketersediaan oksigen terlarut di perairan. Hasil DO pada penelitian dengan ratarata $5,03 \mathrm{mg} / \mathrm{L}$. Kandungan DO di perairan yang dapat ditolerir oleh organisme akuatik terutama mikroalga adalah tidak kurang dari 5 $\mathrm{mg} / \mathrm{L}$ (Maresi et al, 2015).

\section{KESIMPULAN}

Berdasarkan hasil penelitian yang dilakukan, jenis mikroalga Chlorophyta yang ditemukan di Sungai Kasie Kota Lubuklinggau, terdiri dari: 4 Kelas, 6 Ordo, 7 Famili, 7 Genus, dan 9 Spesies. Indeks keanekaragaman mikroalga Chlorophyta termasuk dalam kategori "kecil atau rendah".

\section{UCAPAN TERIMA KASIH}

Penulis mengucapkan terimakasih kepada bapak Dr. Rudi Erwandi, M.Pd selaku Ketua STKIP PGRI Lubuklinggau yang telah memberikan dana untuk kegiatan penelitian ini, dan ibu Endang Suswati, M.Pd selaku kepala laboratorium biologi STKIP PGRI Lubuklinggau yang telah memfasilitasi kegiatan penelitian ini.

\section{REFERENSI}

Andriansyah., Setyawati, T.R \& Lovadi, I. 2014. Kualitas Perairan Kanai Sungai Jawi dan Sungai Raya Dalam Kota Pontianak Ditinjau Dari Struktur Komunitas Mikroalga Perifitik. Jurnal Protobiont 3: 61-70.

Endrawati, H \& Riniatsih, I. 2013. Kadar Total Lipid Mikroalga Nannochloropsis oculata yang dikultur dengan suhu yang berbeda. Buletin Oseanografi Marina. 2(1): 25-33

Harmoko., Triyanti, M \& Aziz, L. 2018. Eksplorasi Mikroalga Di Sungai Mesat
Kota Lubuklinggau. Biodidaktika: Jurnal Biologi dan Pembelajarannya, 13: 19-23.

Harmoko \& Sepriyaningsih. 2017. Keanekaragaman Mikroalga di Sungai Kati Kota Lubuklinggau. Scripta Biologica, 4(3): 201-205.

Harmoko \& Sepriyaningsih. 2018. Keanekaragaman Mikroalga Chlorophyta Di Sungai Kelingi Kota Lubuklinggau Sumatera Selatan. Jurnal Pro-Life, 5(3): 666-676.

Junaidi, F.F. 2014. Analisis Distribusi Kecepatan Aliran Sungai Musi (Ruas Jembatan Ampera Sampai Dengan Pulau Kemaro). Jurnal Teknik Sipil dan Lingkungan 2(3): 542-552.

Maresi, S.R.P., Priyanti., \& Yunita, E. 2015. Mikroalga Sebagai Bioindikator Saprobitas Perairan Di Situ Bulakan Kota Tangerang. Al Kauniyah; Jurnal Biologi. 8 : 113-122.

Pangestu, H \& Haki, H. 2013. Analisis Angkutan Sedimen Total Pada Sungai Dawas Kabupaten Musi Banyuasin. Jurnal Teknik Sipil dan Lingkungan. 1(1) 103-109.

Sari, R.M., Ngabekti, S \& Martin, F.P. 2013. Keanekaragaman Fitoplankton Di Aliran Sumber Air Panas Condrodimuko Gedongsongo Kabupaten Semarang. Unnes Journal of Life Science, 2 (1) 9-15.

Satriani., Golar \& Ihsan, M. 2013. Persepsi Dan Sikap Masyarakat Terhadap Penerapan Program Pemberdayaan Di Sekitar Sub Daerah Aliran Sungai Miu (Kasus Program SCBFWM Di Desa Simoro Kecamatan Gumbasa Kabupaten Sigi). Warta Rimba, 1(1): 1-10.

Siahaan R, Indrawan A, Soedharma D, dan Prasetyo LB. 2011. Water quality of cisadane river, West Java-Banten. Jurnal Ilmiah Sains, 11(2): 268-273.

Siregar. 2011. Identifikasi Dominasi Genus Alga pada Air Boezem Morokembrangan sebagai Sistem High Rate Algae Pond (HRAP). Surabaya: Jurusan Teknik Lingkungan FTSP-ITS. 